\title{
The impact of education communication skills on emotional regulation, resilience and marital satisfaction of mothers of hearing-impaired children
}

\author{
$\underline{\text { Leila Moghtader }}^{1}$ (D), Bahman Akbari ${ }^{2}$ iD \\ ${ }^{1}$ Corresponding author; Department of Psychology, Rasht Branch, Islamic Azad University, Rasht, Iran \\ Tel: $+981333501139 \quad$ Email: moghtaderleila@yahoo.com \\ ${ }^{2}$ Department of Psychology, Rasht Branch, Islamic Azad University, Rasht, Iran
}

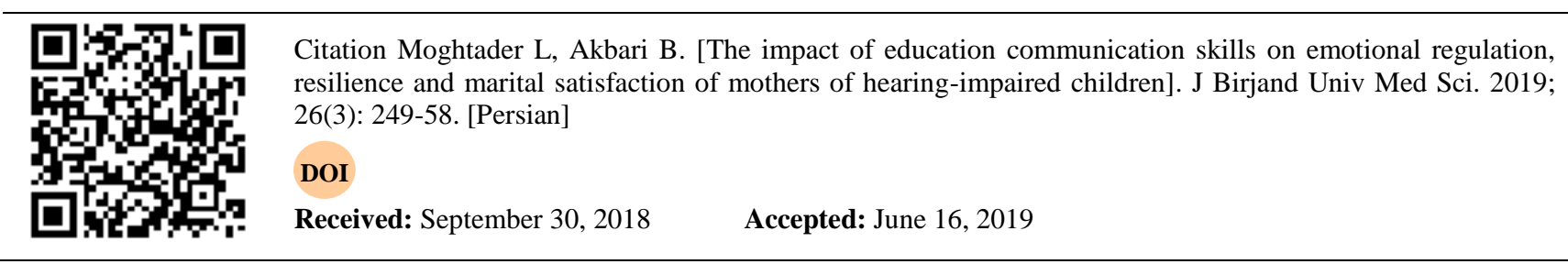

\begin{abstract}
Background and Aim: More than $90 \%$ of hearing-impaired children have hearing parents and their parents do not know how to communicate with these children. The aim of this study was to investigate the impact of education communication skills on bemotional regulation, resilience and marital satisfaction of mothers of hearing-impaired children.

Materials and Methods: The research was a quasi-experimental with pre-test and post-test design with the control group. The statistical population were the mothers of hearing-impaired children under 7 years old in Rasht that was referred to the Pejvak Deafness Clinic in 2017. 40 mothers were selected by convenience sampling and were randomly divided into two groups of intervention (20 people) and control (20 people). Granofsky Emotional Regulation Questionnaire, Conner \& Davison (CD-RIS) and Enrich Marital Satisfaction Questionnaire (ENRICH 47) they were used as research tools. The effective communication skills education program, 8 sessions for mothers in the intervention group were held and the control group received no education. Descriptive statistics including: frequency, percentage, mean, standard deviation and standard error for data description were used and also chi-square, independent t-test, paired t-test, Levin, eta squared, covariance analysis, Kolmogorov-Smirnov and Box were used for data analysis at the significant level of 0.05 .
\end{abstract}

Results: The results showed that communication skills education led to significant differences in the post test of the experimental group and the comparison of the meanings showed an increase in resiliency, emotional regulation and marital satisfaction in the experimental group $(\mathrm{p}<0.01)$.

Conclusion: It can be concluded that by education of effective communication skills, it is possible to increase in marital resilience and marital satisfaction, as well as emotional regulation in the children with hearing-impaired children was obtain.

Key Words: Effective Communication Skills; Emotional Regulation; Resilience; Marital Satisfaction; Hearing-Impaired 


\section{تأثير آموزش مهارتهاى ارتباط مؤثر بر تنظيم هيجانى، تاب آورى و رضايت زناشويى مادران كودكان كرشنوا}

ليلا مقتدر 'DiD)، بهمن اكبرى

جִكيله زمينه و هدف: بيش از •و درصد از كودكان آسيبديده شنوايى، داراى والدين شنوا هستند و والدين آنها شيوه ارتباط با با اين كودكان

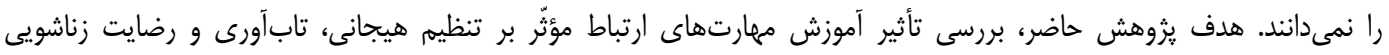
مادران كودكان كمثنوا بود.

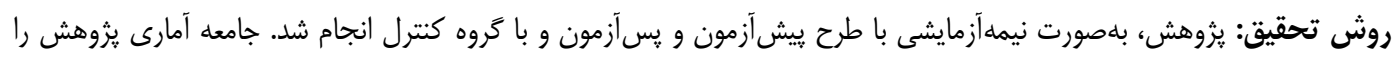

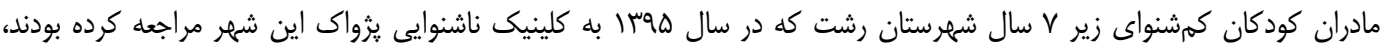

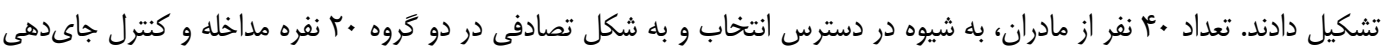

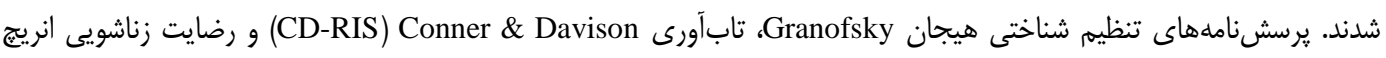

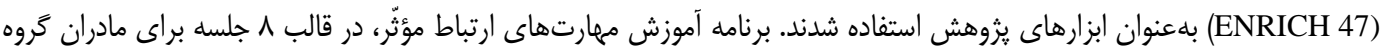

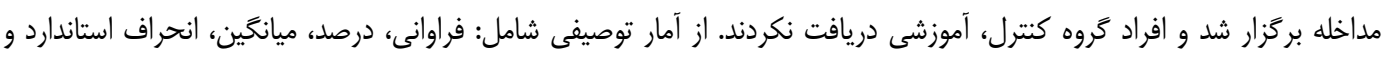

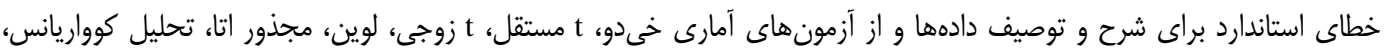

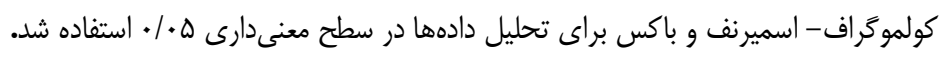

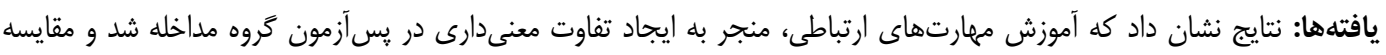

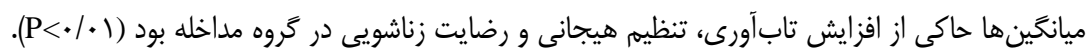

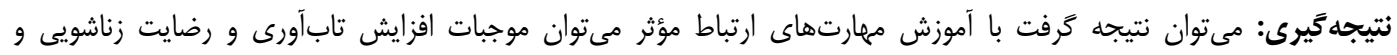

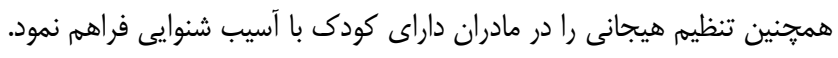
وازههاى كليدى: مهارتهاى ارتباط مؤثر؛ تنظيم هيجانى؛ تابآورى؛ رضايت زناشويى؛ كمشنوا

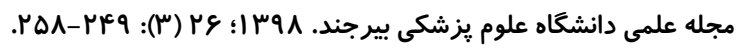
دريافت: • 
كودى ناشنوا بود (I)، II). همجنين مطالعات، آموزش مقله مهارتهاى مقابله با تنيدگى را بر كاهش تنيدگى و افزايش

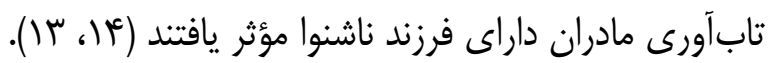

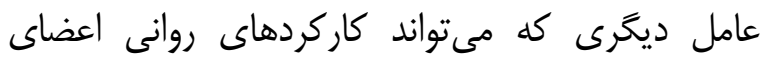
خانواده را در قالب تفكر، خلق و رفتار بجهبود دهد و توان ماند مقابله

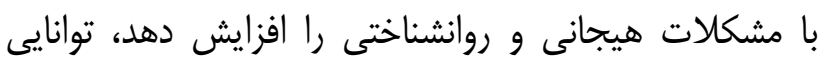

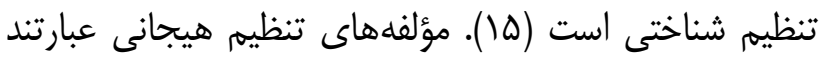

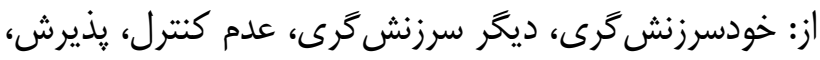

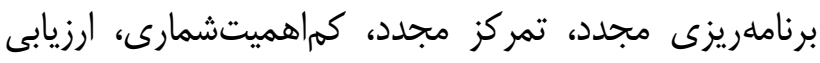

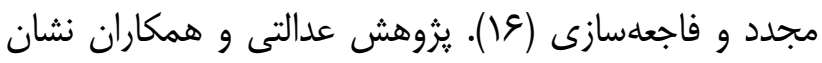

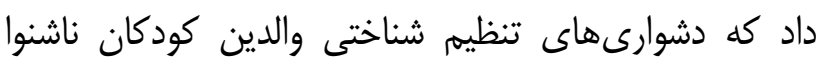

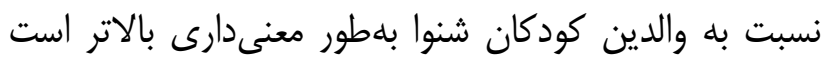

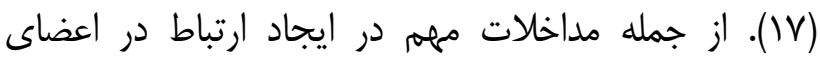

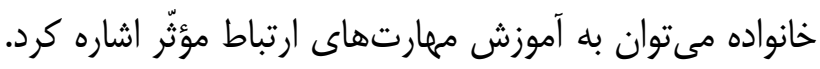

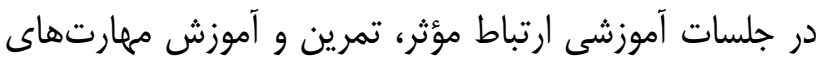

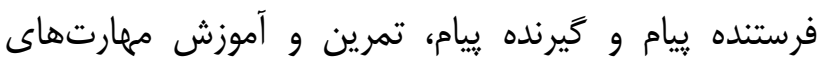

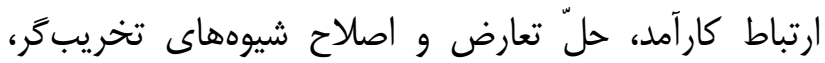

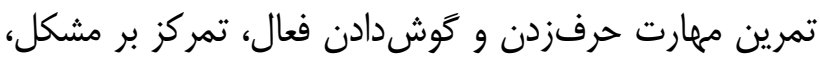
تشخيص تنش، تصديق تفاوتها، درخواست بازخوردين

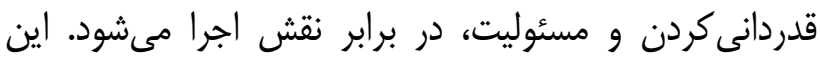

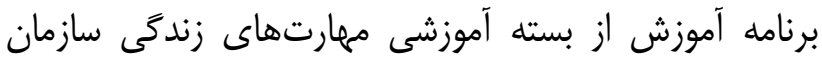

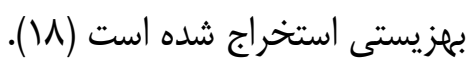

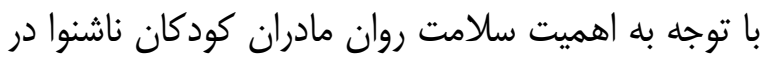
توجه و مراقبت از اين كودكان و با عنايت به اين اينكه تاكنون

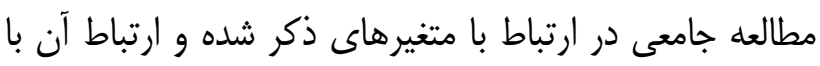

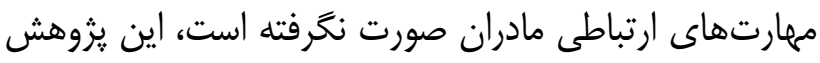

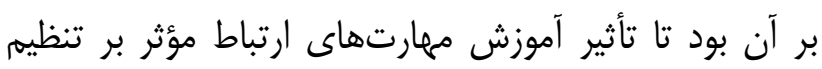

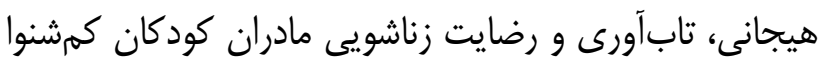
را مورد مطالعه قرار دهد.

شنوايى يكى از مهمترين توانايىهاى حسى است كه

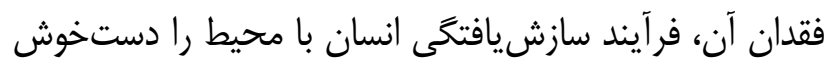

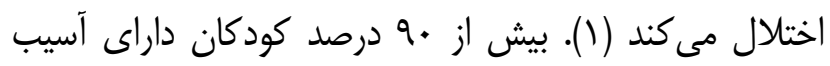

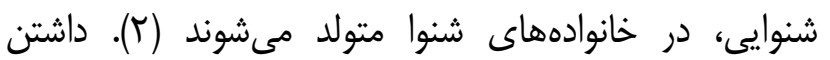

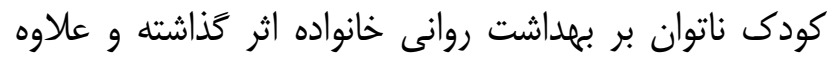

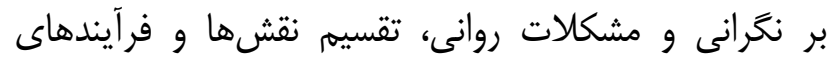

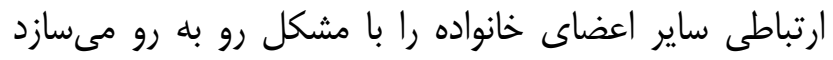

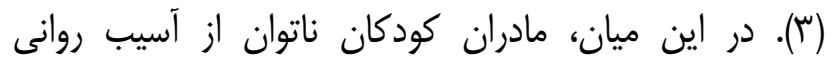
بيشترى برخوردارند؛ هرا كه مادران وقت و احساس مسئوليت آنسان بيشترى راصرف كودكان نموده و حضور آنها در خانه بسيار

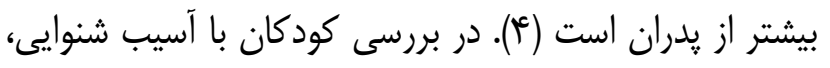

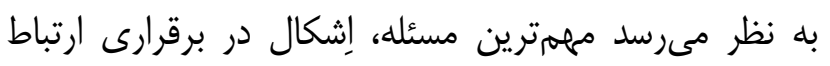
است (ه). Van Gent و همكاران دريافتند كه كيفيت ارتباط والدين با فرزندان، باعث احساس ارزشمندى در فرد ناشنوا مى شود (†). يكى از متغيرهايى كه مى تواند به شكل منفى تحت تأثير

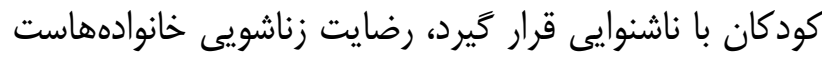

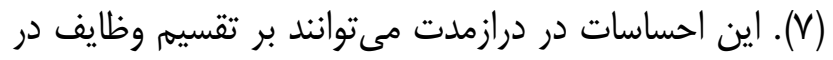

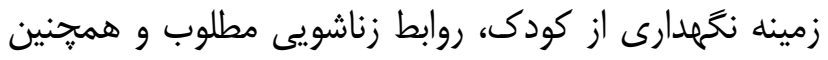

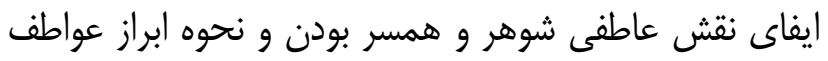

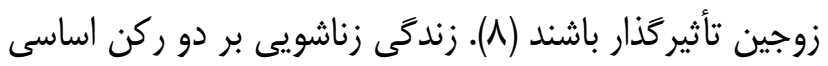

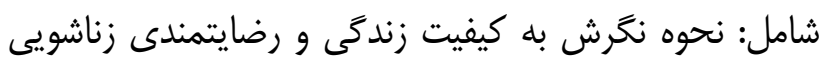

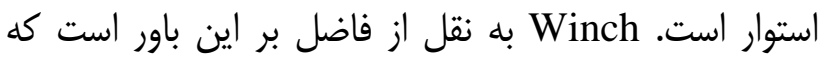

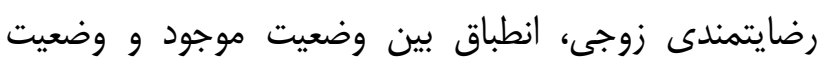
مورد انتظار است (9). از ديخر عوامل مؤثر بر مراقبت از كودى ناشنوا، تابآورى

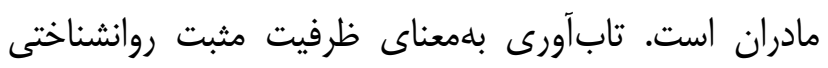

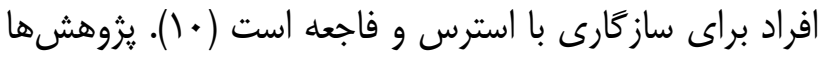
بيانكر وجود رابطه بين تابآورى و سلامت رواريا روانى والدانين

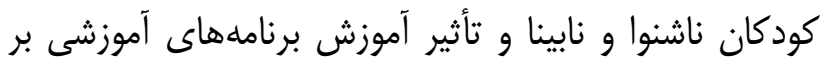

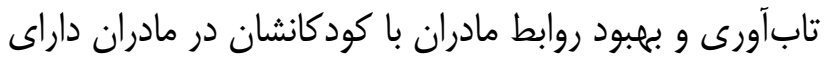


كنترل هيج گونه مداخلهاى صورت نخرفت. بعد از اتمام دوره،

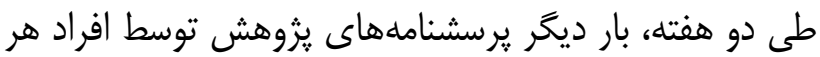

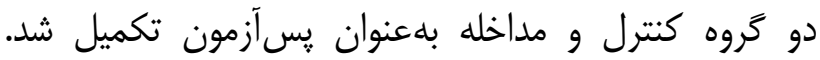
بلمنظور رعايت ملاحظات اخلاقى، يوشيدهماندن اطلاعات شخصى و خروج از مطالعه در صورت عدم تمايل به ادامه

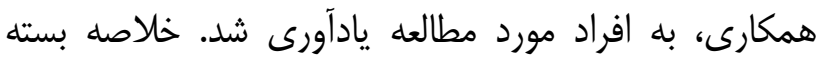

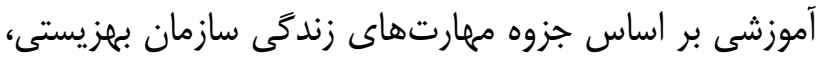

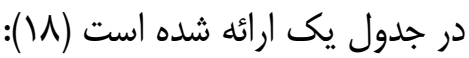

\section{Conner \& Davison مقياس متابآورى}

Davison و Conner اين مقياس كه توسط d (CD-RTSC)

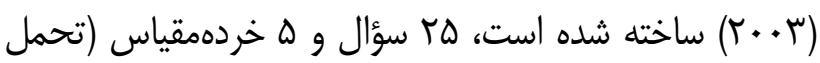

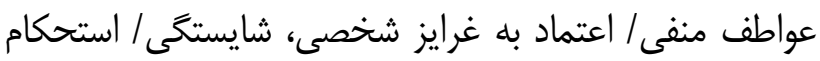
شخصى، هذيرش عواطف مثبت/ روابط امن، مهار، معنويت) دارد كه بر اساس مقياس ليكرت در دامنهاى بين صفر (كاملاً

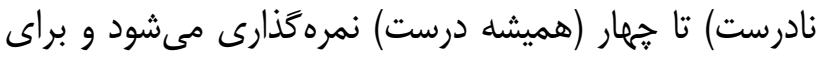

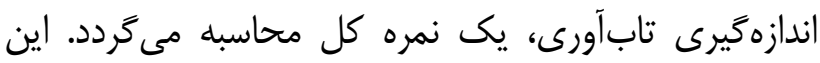

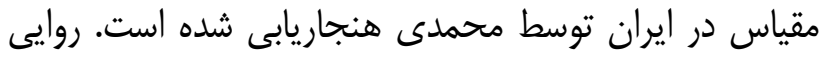

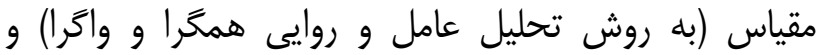

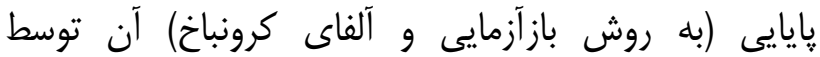
سازندكان آزمون در گروههاى مختلف (عادى و در مخاطره) احراز شده است. در ايران، سامانى و همكاران إنان دايايى مقياس

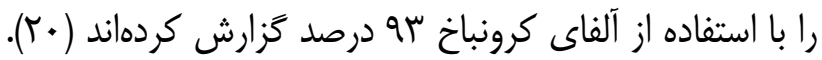

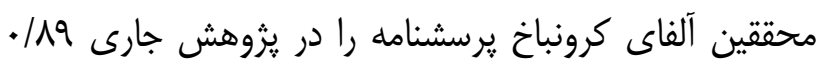
به دست آوردند.

يرسشنامه تنظيم شناختى هيجان: اين يرسشنامه كه

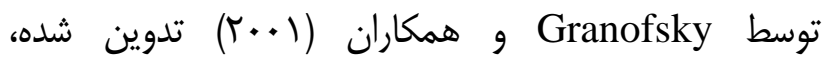
يرسشنامهاى جندبعدى و يك ابزار خودگزارشدهى است كهان

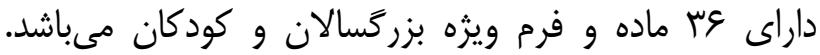

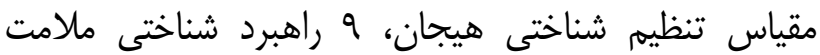

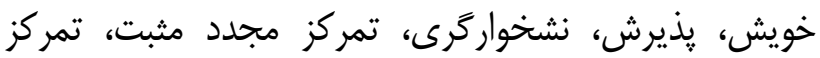

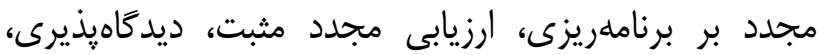

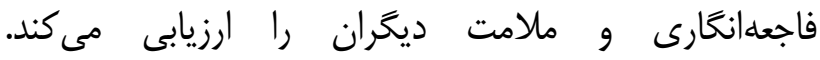

\section{روش تحقيق}

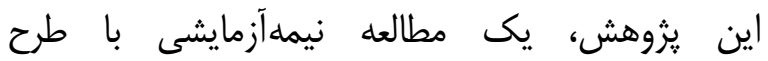

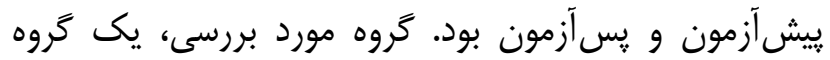

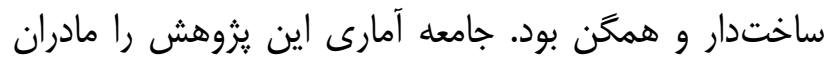

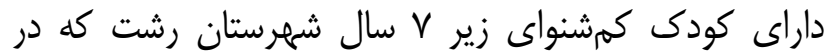

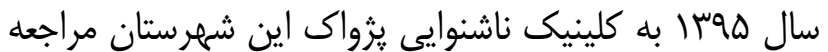

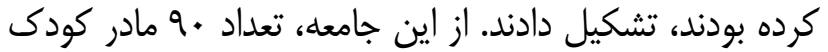

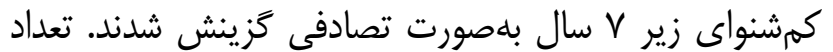

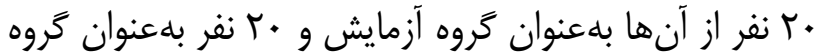

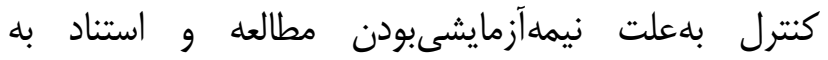
يزوهشهاى مشابه انتخاب شدند (19).

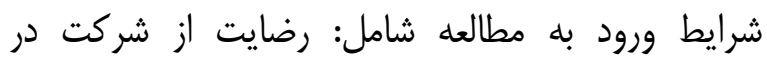
يزوهش، داشتن كودى كمشنوا با سن زير V سال، نمرات

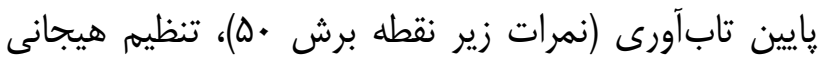

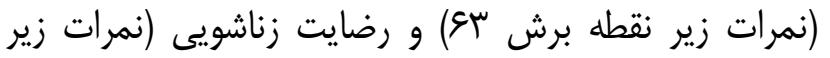
نقطه برش (أ) در ييشآزمون بود. شرايط خروج از مطالعه نيز

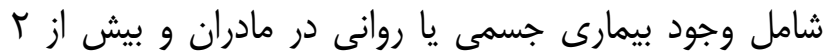
جلسه غيبت مادران در جلسات آموزشى بود. افراد گروهها به يرسشنامههاى تنظيم شناختى هيجان

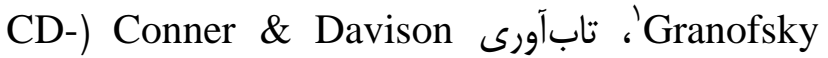
(RIS

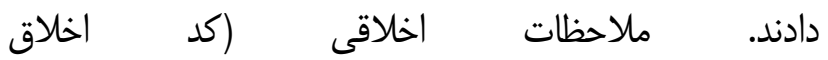
(IR.IAU.RASHT.REC.1395.84 آكاهانه از شركت در يثوهش و خروج از تحقيق در صورت عدم تمايل به ادامه همكارى نيز رعايت گرديد و در اين رابطه دره كد اخلاق IR.IAU.RASHT.REC.1395.84 از كميته اخلاق دانشعاه آزاد اسلامى واحد رشت دريافت كرديد. شيوه برگزارى جلسات بهصورت بحث گروهى بود و وان مطالب آموزشى توسط درمانگر و كمكدرمانگر ارائه شد. مداخله در قالب ^ جلسه هأ دقيقهاى ارائه شد. در مورد گروه

\footnotetext{
${ }^{1}$ Granofsky Emotional Adjustment Questionnaire

${ }^{2}$ Conner \& Davison Resiliency Questionnaire (CD-RIS)

${ }^{3}$ Enrich Marital Satisfaction Questionnaire (ENRICH 47)
} 
جدول ا - محتواى جلسات آموزشى مهارتهاى ارتباطى

\begin{tabular}{|c|c|}
\hline محتواى جلسات & جلسات \\
\hline معرفى، بيان اهداف و محتوا، تشويق به مشاهده و رديابى رفتارهاى كودى با هدف تغيير رفتار كودى & اول \\
\hline آموزش استراتثىهايى براى ايجاد ارتباط مثبت با كودى و آموزش مهارتهاى فرستنده و كَيرنده يِام & دوم \\
\hline آموزش استراتزىهاى افزايش رفتارهاى مثبت و حل تعارض و اصلاح شيوههاى تخريبكر & سوم \\
\hline آموزش استراتثىهايى همانند: آموزش اتفاقى، تكنيك يرسيدن، كَفتن، انجامدادن & 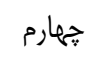 \\
\hline آموزش درباره يِامدهاى منفى تنبيه و استراتزىهايى براى مقابله با سوء رفتار كودى & ينجمم \\
\hline آموزش استراتثىهاى جايخزين تنبيه به اشكال ييشرفته (شامل: ييامد منطقى، محرومسازى و زمان ساكت) & ششم \\
\hline آموزش برنامه روزانه ييروى، تصحيح رفتار و جارت رفتارى با هدف مديريت سوء رفتار كودى توسط والدين & 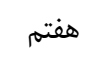 \\
\hline شناسايى موقعيتهاى يرخطر و به كارگيرى استراتزىهايى در قالب تكنيك فعاليتهاى برناملريزىشده & هشتم \\
\hline
\end{tabular}

"رضايت كم" و نمره بالاتر از •9 نشانكر "ارضايت زناشويى

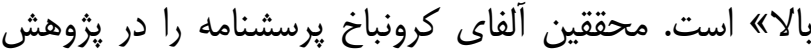
جارى س/N/ • به دست آوردند.

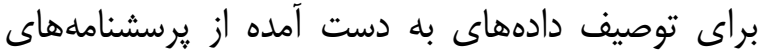
بيانشده، از شاخصها و روشهاى آمار توصيفى شامل: فراوانى، درصد، ميانكَين، انحراف استاندارد و خطاى استاندارد إنارد

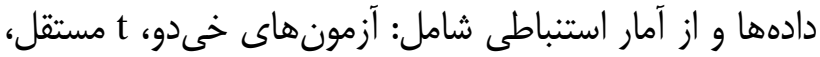

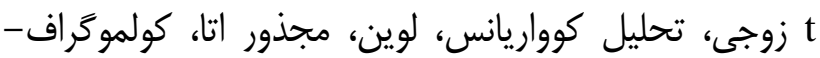

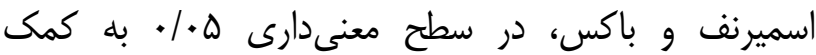

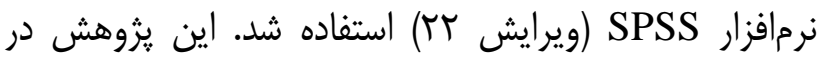

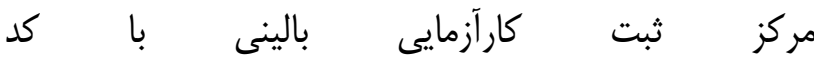
IRCT2016714028931N3

يافتهها

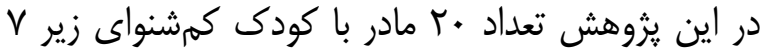

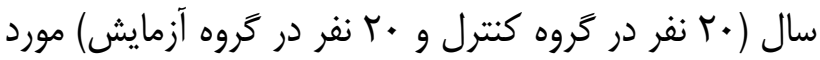

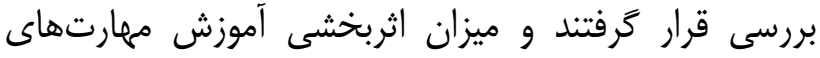

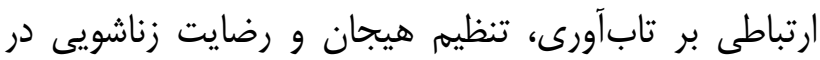
كروه كنترل بررسى شد. تحليل توصيفى دادهها در خصوص تران مؤلفهاي جمعيتشناختى نشان داد كه ميانكين و انحراف

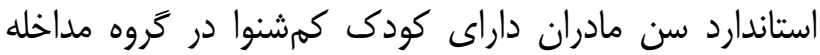

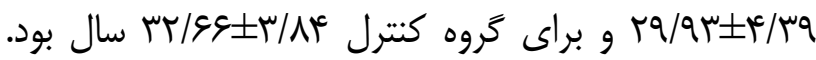
آزمون t مستقل بيانكر عدم وجود تفاوت معنىدار از نظر متغير كروا

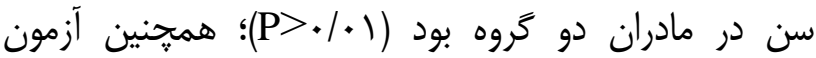

نمرهذذارى اين يرسشنامه بر اساس درجهبندى ليكرت بوده و

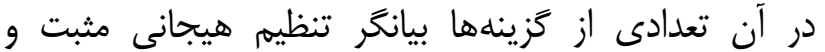
بارهاى بيانكر تنظيم هيجانى منفى هستند. ضريب آلفا براى

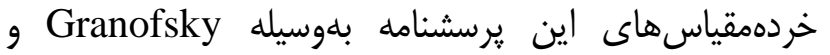

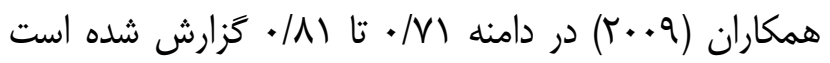

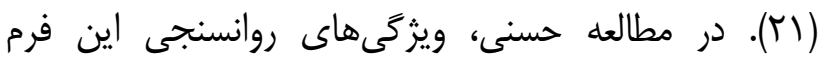

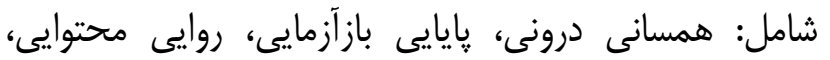

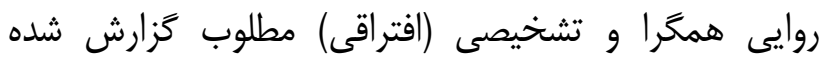

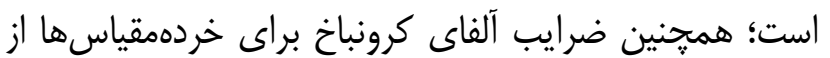

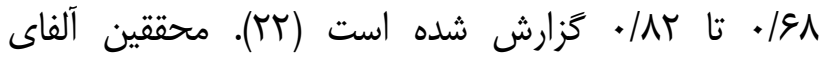

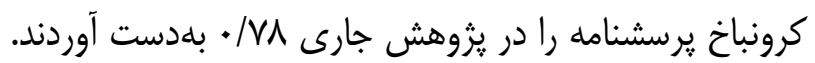

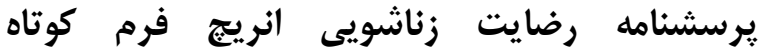
ENRICH-47): برسشنامه رضايت زناشويى انريج توسط Olson بلهمنظور ارزيابى زمينههاى بالقوه مشكلزا و و شناسايى زمينههاى قدرت و يربارسازى روابط زناشويى به كار مئرودا.

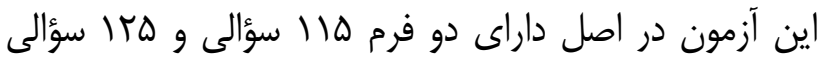

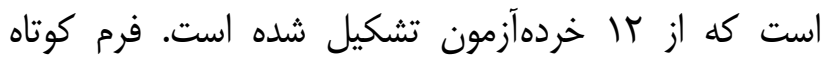

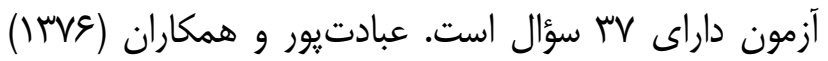

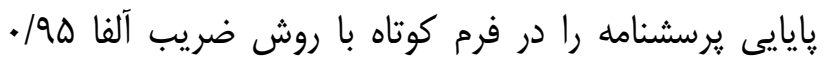

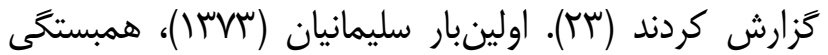

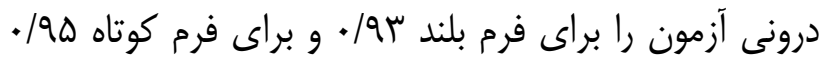

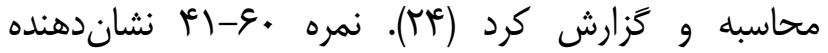

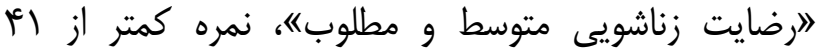


خىدو بيانگر عدم وجود تفاوت معنىدار از نظر متغيرهاى اطلاعات جمعيتشناختى در جدول ب بيان شده است.

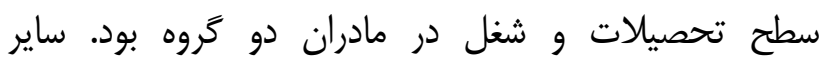
جدول r- مقايسه توزيع فراوانى افراد مورد مطالعه بر حسب متغيرهاى دموكَ افيك در تَروه مداخله و كنترل

\begin{tabular}{|c|c|c|c|c|}
\hline سطح معنىدارى & 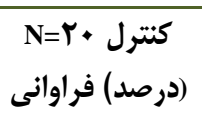 & $\begin{array}{l}\text { N=r+ مداخله فراوانى } \\
\text { (درصد) }\end{array}$ & تَروه & 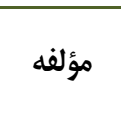 \\
\hline \multirow{2}{*}{$\mathrm{P}=\cdot / \varepsilon \mathrm{V}$} & $(90) 19$ & $(q \cdot) 11$ & دائم & \multirow{2}{*}{ تأهل } \\
\hline & (D) $)$ & $(1 \cdot)^{r}$ & موقت & \\
\hline \multirow{2}{*}{$\mathrm{P}=\cdot / \Delta q$} & $(t \cdot) \wedge$ & $(\varepsilon \cdot) 1 T$ & شاغل & \multirow{2}{*}{ شغل } \\
\hline & (4.) Ir & $\left(x^{c} \cdot 1\right)$ & خانه دار & \\
\hline \multirow{3}{*}{$\mathrm{P}=\cdot / \varepsilon \Delta$} & $(r \cdot)^{r}$ & $\left(r^{c} \cdot 1\right)$ & دييلم & \multirow{3}{*}{ تحصيلات } \\
\hline & $(\Delta \cdot))$. & $(\Delta \cdot))$. & كارشناس & \\
\hline & $(\mu \cdot \xi$ & $(1 \cdot) r$ & كارشناس ارشد & \\
\hline
\end{tabular}

جدول بـ- مقايسه ميانكَين نمرات تابآورى تنظيم هيجان و رضايت زناشويى در دو تروه قبل و بعد از مداخله

\begin{tabular}{|c|c|c|c|c|c|}
\hline ميانتين تغييرات & معنىدارى سطح & $\begin{array}{c}\text { بعد مداخله } \\
(\text { Mean } \pm \text { SD) }\end{array}$ & $\begin{array}{c}\text { قبل مداخله } \\
\text { (Mean 土SD) }\end{array}$ & تروه & مؤلفه \\
\hline r & $\mathrm{P}=\cdot / \cdot r$ & 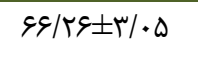 & 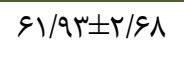 & آزمايش & \\
\hline.$/ \cdot V$ & $\mathrm{P}=\cdot /$ L & $\varepsilon \varphi / q r \pm r / \varepsilon \Delta$ & $g q / \Lambda \varepsilon \pm r / g r$ & كنترل & تابآورى \\
\hline $\mathrm{P}<\cdot / \cdot \cdot 1$ & - & $\mathrm{P}=\cdot / \cdot \mathrm{r}$ & $\mathrm{P}=\cdot / 419$ & tتست t & \\
\hline$F / N$ & $\mathrm{P}=\cdot / \cdot 1$ & $\mid T F / \mathscr{C} \Phi \pm T / T \&$ & $119 / \varepsilon \cdot \pm r / 4 r$ & آزمايش & \\
\hline.$/ 9 V$ & $\mathrm{P}=\cdot /$ Trf & $\mid r \Delta / r \cdot \pm r / v r$ & $\mid r F / \Delta r \pm T / F r$ & كنترل & تنظيم هيجان \\
\hline $\mathrm{P}<\bullet / . .1$ & - & $\mathrm{P}=\cdot / \cdot r$ & $\mathrm{P}=\cdot / \kappa \mu r$ & تست tt & \\
\hline$F / N$ & $\mathrm{P}=\cdot / \cdot \cdot r$ & $V G / r G \pm F / V \Lambda$ & $\checkmark / / \mathcal{c}+ \pm \kappa / q \varepsilon$ & آزمايش & \\
\hline.$- / T \&$ & $\mathrm{P}=\cdot / \Delta \wedge \vee$ & $V T / r \cdot \pm r / \mathcal{E}$ & $V \Psi / \mathscr{\varepsilon} \pm V / \widetilde{\varphi}$ & كنترل & رضايت زناشويى \\
\hline $\mathrm{P}<\cdot / \cdot . \cdot 1$ & - & $\mathrm{P}=\cdot / \cdot \cdot \mathrm{F}$ & $\mathrm{P}=\cdot / \mu \mathrm{I}$ & تست & \\
\hline
\end{tabular}

جدول به، ميانگين و انحراف استاندارد هر يك از كنترل نيز نشان داد كه ماتريس كوواريانس متغيرهاى وابسته

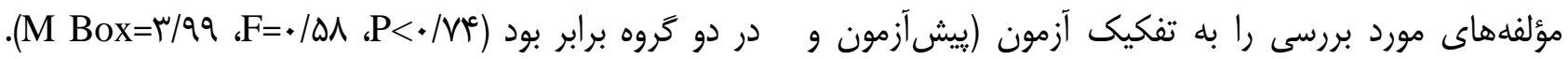

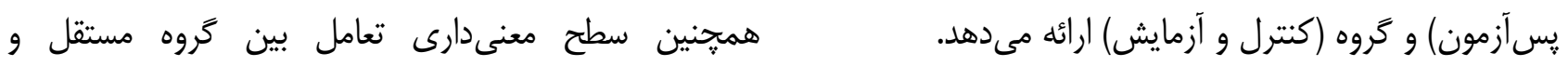

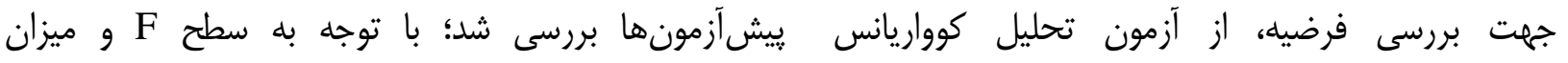

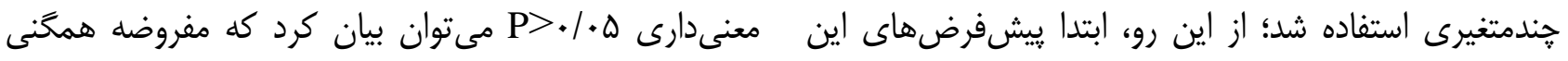

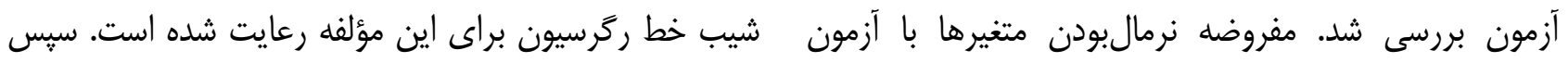

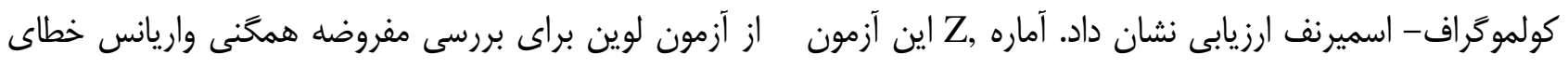

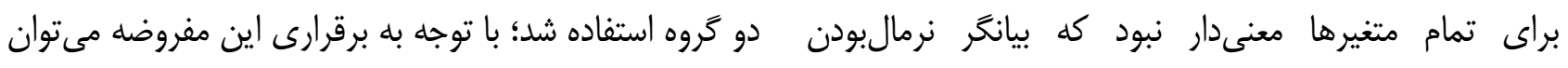

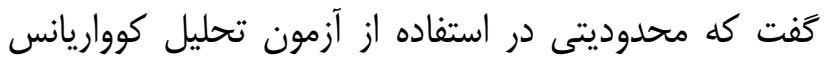
متغير هاست.

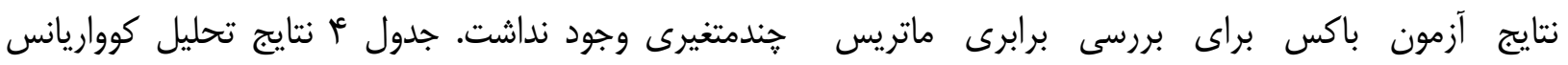

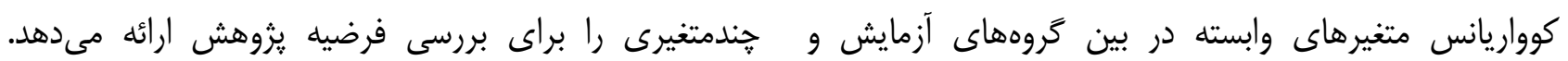


جدول f - نتايج تحليل كوواريانس جندمتغيرى اثربخشى آموزش بر تنظيم هيجانى، تابآورى و رضايت زناشويى

\begin{tabular}{|c|c|c|c|c|c|c|}
\hline توان آزمون & معنى دارى & $\mathbf{F}$ & ميانكَين مجذور & Df & مجموع مجذور & مؤلفه \\
\hline$\cdot / \Lambda$ & .1 .1 & If $\Delta / V V F$ & $\mid r N / \Delta \Delta D$ & 1 & $I \Psi N / \Delta \Delta D$ & تنظيم هيجان \\
\hline.$/ V G$ & $.1 \cdot 1$ & SN/DTF & $101 / 98 \varphi^{c}$ & 1 & $101 / 984$ & تابآورى \\
\hline . $/ \Lambda 9$ & .1 .1 & GN/DYF & $101 / 98 t^{\circ}$ & 1 & $101 / 98 t^{\circ}$ & رضايت زناشويى \\
\hline
\end{tabular}

تنيدگى و تنظيم هيجان مادران داراى فرزند ناشنوا مؤثر است

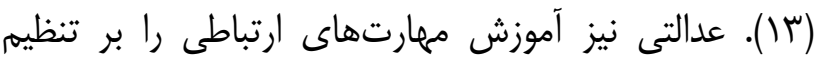

شناختى زوجين مؤثر يافت (IV).

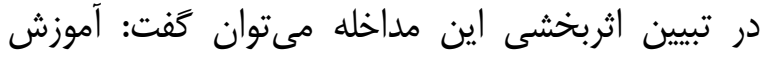

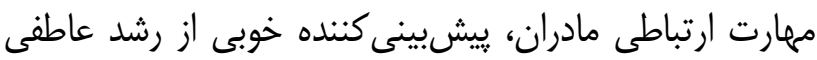

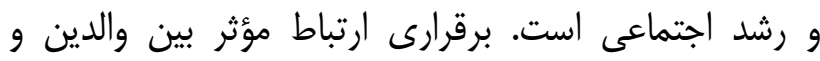

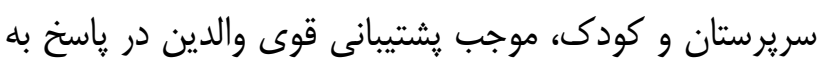

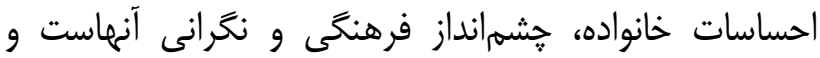

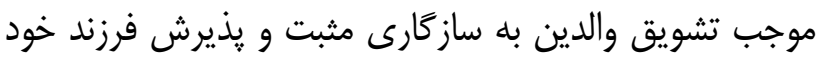

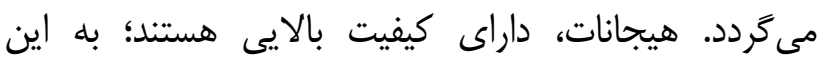
صورت كه مىتوانند باعث واكنش مثبت يا منفى در افراد داد داديث شوند؛ بنابر اين زمانى كه هيجانات شديد يا طولانى مىشوند و

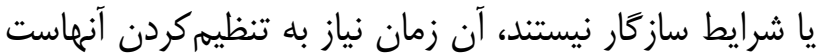

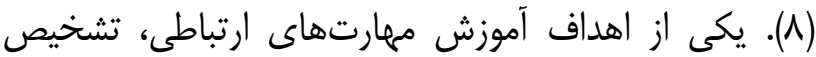

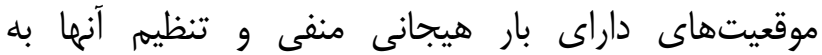

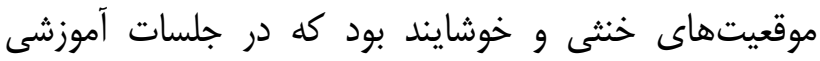
تأمين شد.

همجنين نتايج يروهش بيانگر تأثير آموزش مهارتهاى

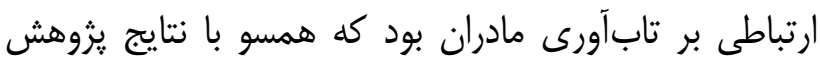

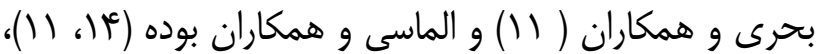

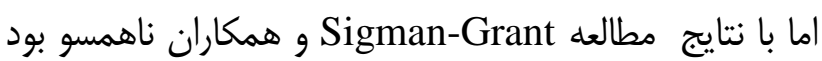
Sigman-Grant و همكاران در مطالعه خود نشان دادند

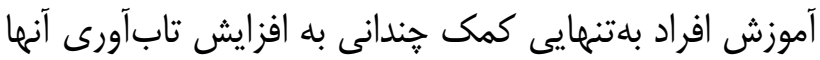

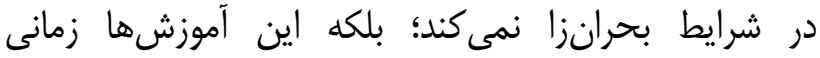

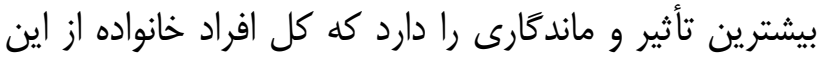

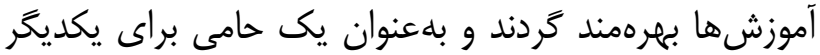

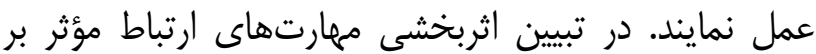

نتايج تحليل كوواريانس جندمتغيرى ارائهشده در جدول ع نشان مىدهد كه آموزش مهارتهاى ارتباطى منجر به ايجاد

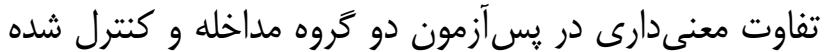
و مقايسه ميانخينها حاكى از افزايش تابآورى، تنظيه

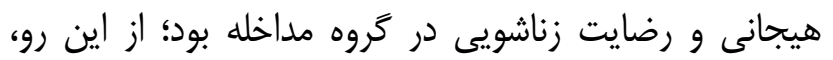

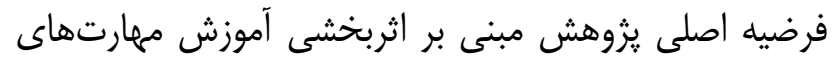

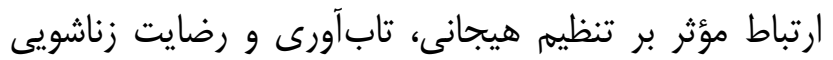

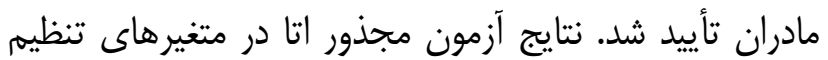

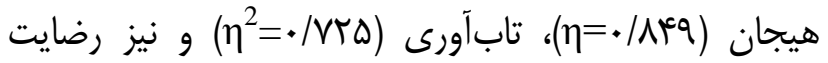

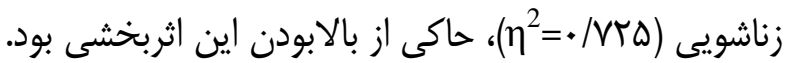

يكى از مشكلات داشتن كودى ناتوان، تأثيريذيرى خانواده بهخصوص مراقب اصلى يعنى مادر از اين موقعيت

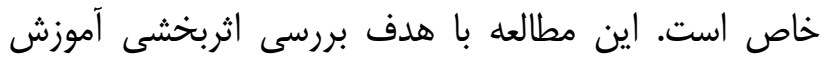

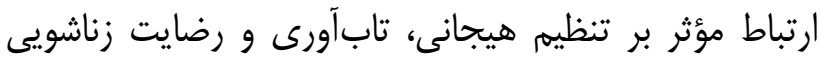
مادران كودكان كمشنوا در سال هوسا انجام شد. تحليل كواريانس جندمتغيره نشان داد، آموزش ارتباط مؤثر بر تنظيم هيجانى، تابآورى و رضايت زناشويى مادران كودكان كمشنوا مؤثر است. اين نتيجه، با يافتههاى براب برخى

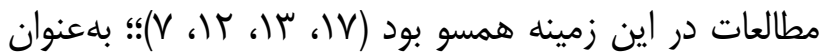

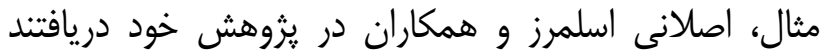
ميزان تنظيم هيجانى و بهبود روابط مادران با كودكانشان در مادرانى كه تحت آموزش برنامه تابآورى قرار گرفتهاند، از

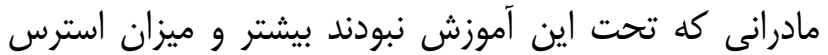

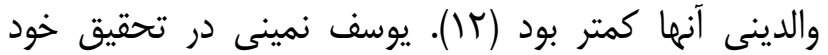

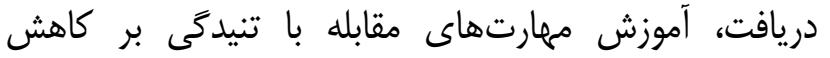


دلايل اثربخشى برنامه، مشاركت فعال مادران در جلسات و

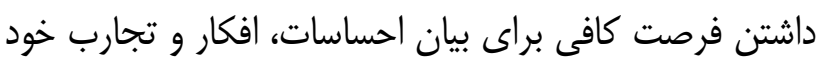
بود كه روند برنامه را يويا نمود.

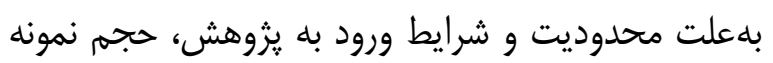

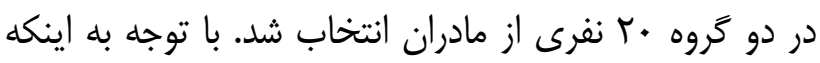

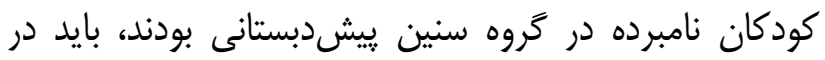

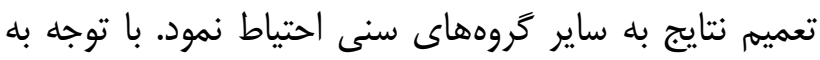

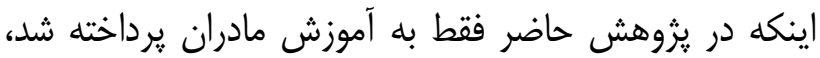

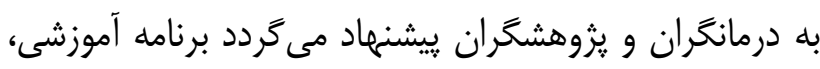

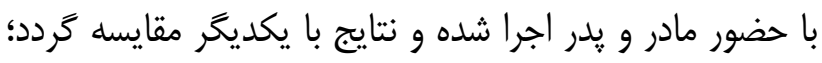

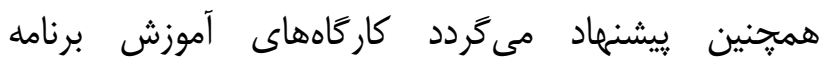

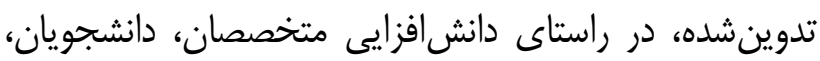

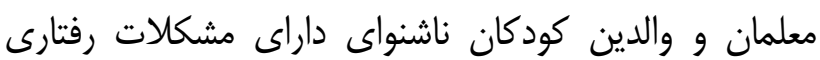

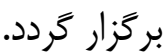

\section{نتيجه كيرى}

با توجه به اثربخشى آموزش مهارتهاى ارتباط مؤثر بر تنظيم هيجانى، تابآورى و رضايت زناشويى مادران كودكان

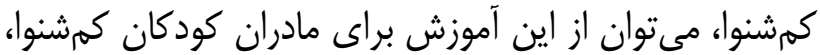

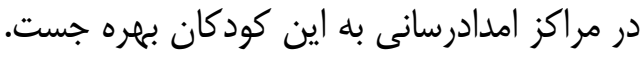

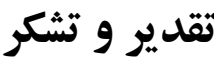

اين مقاله حاصل طرح مصوب دانشخاه آزاد اسلامى واحد

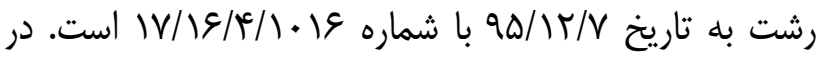

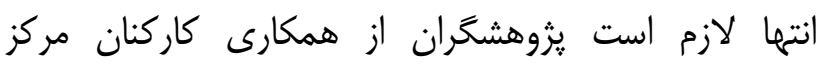

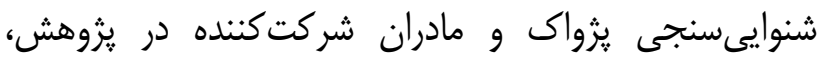
كمال تقدير و تشكر را بجا آورند.

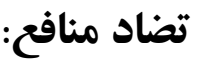

نويسندكان مقاله اعلام مى دارند كه هيج كَونه تضاد منافعى در يزوهش حاضر وجود ندارد.
متغير تابآورى مىتوان به اين امر اشاره كرد كه توانايى در

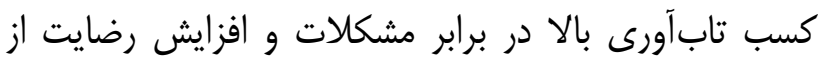

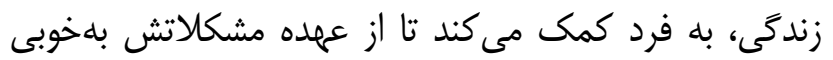

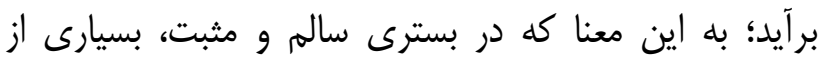

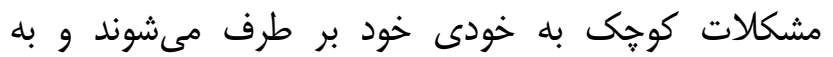
تعارضات نيز بلعنوان يك مسئله نخاه مى شيود. دورههاى

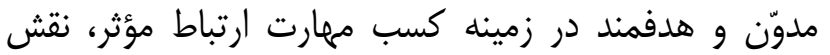
اساسى در حفظ تعادل و سلامت روانى - اجتماعى خانواده بر إنباط

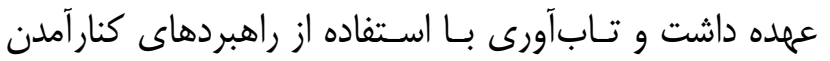
كار آمد و مفيد و تغيير سبك رفتار دابل در افراد مفيد واقع شد.

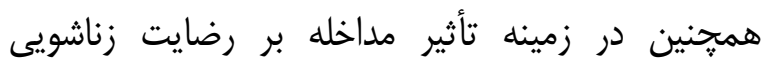
مادران مورد مطالعه، نتايج مطالعه حاضر در راستاى نتايج

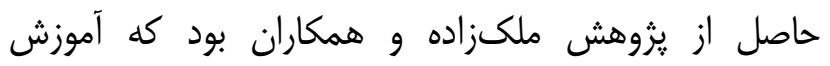

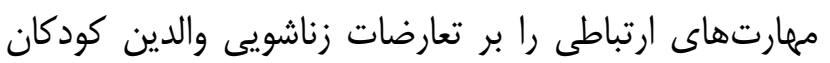

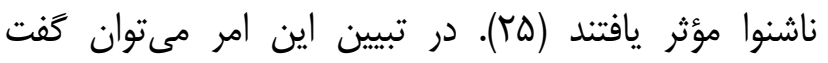
نارضايتى زناشويى زمانى اتفاق مىافتد كه وضعيت موجود بين إنين زوجين در روابط زناشويى با وضعيت مورد انتظار و دلخواه آنها

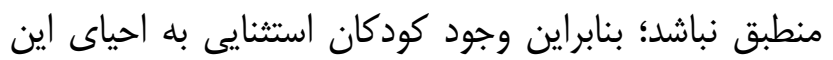
زمينه كمى كرده و نارضايتى زناشويى والدين داراى فرزندان

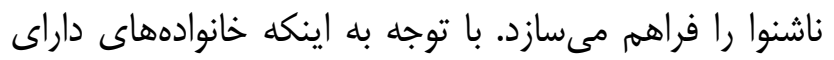

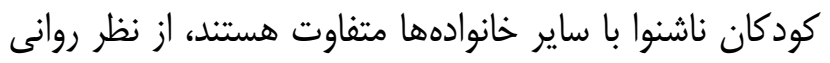

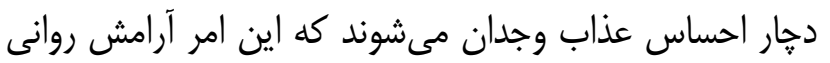

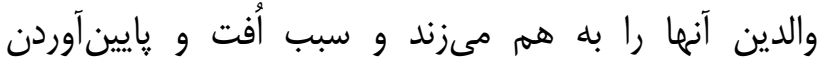

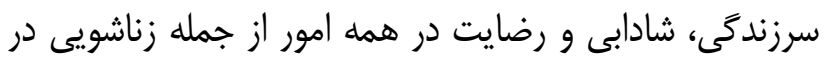

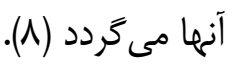

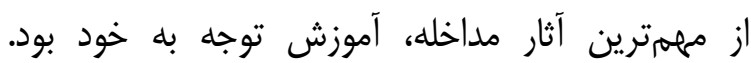

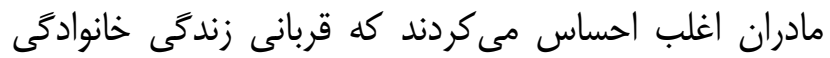

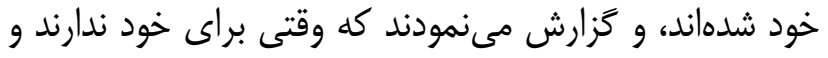

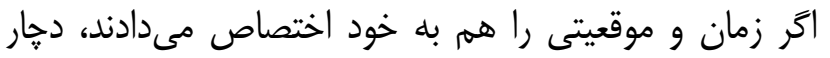

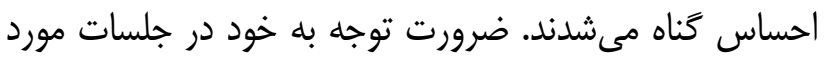

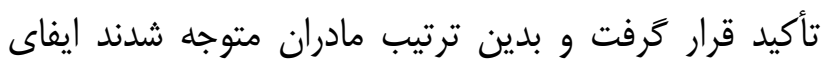
نقش مادرى، متعارض با توجه به خود نيست. يكى دئ ديكر از 
1- Demehri F, Movallali G, Ahmadi V. A Study of Relationship between Early Maladaptive Schemas self-Concept and Behavioral Problems among Deaf Adolescences and Adolescences with Visual Impairment in YAZD City. J Ilam Univ Med Sci. 2015; 23(4): 191-201. [Persian]

2- Chaudhury S. Anxiety and depression in mothers of deaf children: Awareness needed. Commentary. 2014; 7(6): 7201.

3- Kral A, O'Donoghue GM. Profound deafness in childhood. N Engl J Med. 2010, 363: 1438-50. DOI: 10.1056/NEJMra0911225

4- Sigman-Grant M, Hayes J, VanBrackle A, Fiese B. Family resiliency: A neglected perspective in addressing obesity in young children. Child Obes. 2015; 11(6): 664-73. doi: 10.1089/chi.2014.0107.

5- Ataabadi S, Yousefi Z, Moradi A. Investigation of the multiple relations between Emotional Intelligence, Social Skills and self-esteem with Family Communications among Deaf and Hard of hearing adolescents. Intl Res J Appl Basic Sci. 2013; 6(11): 1600-8.

6- Van Gent T, Goedhart AW, Knoors HET, Westenberg PM, Treffers P. Self-concept and ego development in deaf adolescents: a comparative study. J Deaf Stud Deaf Educ. 2012; 17(3): 333-51. doi: 10.1093/deafed/ens002.

7- Arfa M, Ghamarani A, Yarmohamadian A. A Comparison of Vitality, Marital Adjustment and Difficulties in Cognitive - Emotional Regulation in Parents of Deaf Children and Normal Children. J Res Behav Sci 2015; 13(2): 331342. [Persian]

8- Amiri M. The relationship between family function, social support and demographic factors with stress and mental health among parents of deaf children. Research in Psychological Health. 2017; 10(4): 63-75. [Persian]

9- Fazel A, Haghshenas H, Keshavarz Z. Personality traits and life style and the prediction of marital satisfaction among woman nurses. Sociology of Women (Journal of Woman And Society). 2011; 2(3): 139-161.

10- Khodabakhshi koolaee A, Derakhshandeh M. Effectiveness of hope-oriented group therapy on life meaning and resilience in mothers with physical-motor disabled children. Iran J Pediatr Nurs. 2015; 1(3): 15-25. [Persian]

11- Bahri SL, Dehghan Manshadi M, Dehghan Manshadi Z. To Investigate the effect of predicting resiliency and social support in general mental health in parents of deaf and blind children. Exceptional Education. 2014; 1(123): 5-12. [Persian]

12- Aslani Aslmars L. The effect of educational program on quality of life components of mothers with hearing impaired children [Dissertation]. Tehran: University of Social Welfare and Rehabilitation Sciences; 2014. [Persian]

13- Yousefi-Namini AS, Ghobari-Bonab B, Hassanzadeh S, Shokoohi-Yekta M. Development of Behavior Management Program for Mothers of Deaf Children and Studying its Effectiveness on Reduction of Mothers Stress. J Clini Psychol. 2015; 6(3): 95-107. [Persian]

14- Almasi A, Hatami F, Sharifi A, Ahmadijouybari T, Kaviannezhad R, Ebrahimzadeh F. Effectiveness of stress coping skills training on the resiliency of mothers of handicapped children. J Kurdistan Unive Med Sci. 2016; 21(2): 34-42. [Persian]

15- Ghasemzadeh Nasaji S, Peyvastehgar M, Hosseinian S, Mootabi F, Banihashemi S. Effectiveness of cognitive behavioral Interventions on coping responses and cognitive emotion regulation strategies. Journal of Behavioral Sciences. 2010; 4(1): 35-43. [Persian]

16- Daneshmandi S, Izadkhah H, Kazemi Z, Mehrab A. The Effectiveness of Emotional Schema Therapy on Emotional Schemas of Female Victims of Child Abuse and Neglect. J Shahid Sadoughi Univ Med Sci. 2014; 22(5): 1481-1494. [Persian]

17- Edalati A, Redzuan M. Perception of women towards family values and their marital satisfaction. Journal of American Science. 2010; 6(4): 132-7.

18- Naseri H. Life Skills. Tehran: Public Relations Office of the Welfare Organization; 2007. [Persian]

19- Delavar A. Educational and Psychological Research. Tehran: Virayesh; 2011. [Persian] 
20- Samani S, Jokar B, Sahragard N. Effects of Resilience on Mental Health and Life Satisfaction. Iran J Psychiatry Clin Psychol. 2007; 13(3): 290-5. [Persian]

21- Garnefski N, Koopman H, Kraaij V, Ten Cate R. Brief report: Cognitive emotion regulation strategies and psychological adjustment in adolescents with a chronic disease. J Adolesc. 2009, 32(2): 449-54. doi: 10.1016/j.adolescence.2008.01.003.

22- Hasani J. The reliability and validity of the short form of the cognitive emotion regulation questionnaire. Journal of Research in Behavioural Sciences. 2011; 9(4): 229-40. [Persian]

23- Ebadatpour M. Standardization of Marital Communication Patterns Questionnaire in Tehran. [Dissertation]. Tehran: Tarbiat Moallem University; 2001.

24- Soleimanian AA. Investigating the Impact of Irrational Thoughts (Based on Cognitive Approach) on marital dissatisfaction [Dissertation]. Tehran: Tarbiat Moallem University; 1994. [Persian]

25- Malekzadeh A, Ezazi Bojnourdi E, Shahandeh A, Vatankhah H, Bahadori Jahromi S. The Effectiveness of Forgiveness Skill Training on Marital Conflict and Aggression in Parents of Deaf Children. Journal of Exceptional Children Empowerment. 2017; 8(22): 61-9. [Persian] 